\title{
Morphological Study on Gravid Segments of Dipylidium caninum and Management of Dipylidiosis in Dogs
}

\author{
S. Sivajothi* , B. Sudhakara RedDY \\ College of Veterinary Science, Proddatur - 516360, Sri Venkateswara Veterinary University, Andhra Pradesh, India.
}

\begin{abstract}
The present communication is a report about the morphological description of the gravid segments of $D i-$ pylidium caninum infection in non- descriptive dogs in a kennel. Seven adult dogs were showing the history of reduced feed intake, frequent diarrhoea, progressive emaciation and scooting behaviour for eight days in a kennel. Physical examination of the dogs revealed flea infestation, mild abdominal pain and foul smelling stools. One of the dogs showed the passing of white coloured parasitic segments from the anus. Faecal examination showed the presence of D. caninum egg pockets and microscopic examination of the processed parasitic segments were identified as they were gravid segments of D.caninum. Dogs were free from parasitic ova on the ninth day of revisit after administration with praziquantel@10mg/kg bodyweight orally.
\end{abstract}

Keywords $\mid$ Dipylidium caninum, Dogs, Stools, Zoonotic, Praziquantel, Proglottid

Editor | Muhammad Imran Rashid, Department of Parasitology, University of Veterinary and Animal Sciences, Lahore, Pakistan.

Received | September 06, 2018; Accepted | October 14, 2018; Published | December 17, 2018

*Correspondence | S Sivajothi, College of Veterinary Science, Proddatur - 516360, Sri Venkateswara Veterinary University, Andhra Pradesh, India; Email: sivajothi579@gmail.com

Citation Sivajothi S, Reddy BS (2018). Morphological study on gravid segments of dipylidium caninum and management of dipylidiosis in dogs. J. Adv. Parasitol. 5(4): 56-58

DOI | http://dx.doi.org/10.17582/journal.jap/2018/5.4.56.58

Copyright (C) 2018 Sivajothi and Reddy. This is an open access article distributed under the Creative Commons Attribution License, which permits unrestricted use, distribution, and reproduction in any medium, provided the original work is properly cited.

\section{INTRODUCTION}

D ipylidium caninum is one of the common tapeworms of canines. It has the zoonotic importance causing clinical diseases in humans (Narasimham et al., 2013). It is transmitted by the accidental ingestion of the infected flea or louse. The prevalence of D. caninum in dogs has beenreported byvarious researchers in different states of India (Wani et al., 2015; Moudgil et al., 2016). The present paper describes about the morphological study on gravid segments of $D$. caninum along with management of dipylidiosis in dogs.

\section{MATERIALS AND METHODS}

Seven adult dogs in a kennel with the history of reduced feed intake, frequent development of the watery diarrhoea, progressive emaciation and scooting behaviour since eight days were presented at the Veterinary Clinical Complex, College of Veterinary Science, YSR district, Proddatur. All the dogs were dewormed one year back and vaccinated regularly. Clinical examination revealed the congested mucus membranes, dullness, mild dehydration, abdominal pain,foul smelling stools and one dog was passing cucumber seed shaped white coloured parasitic segments from the anus (Figure 1). Passed parasitic segments were collected for further processing. Faecal samples were collected for microscopic analysis.

\section{RESULTS AND DISCUSSION}

Microscopic examination of the fecal sample revealed the presence of D. caninum egg pockets (Figure 2) as per the standard morphology (Soulsby, 1982). The present disease was further confirmed by microscopic examination of stained processed proglottid segments. Parasitic segments were separated and pressed between the two slides, processed and stained. Microscopic examination of the stained segments revealed the presence of egg capsules containing eggs (Figure 3). Presence of egg capsules containing up to 30 eggs is the characteristic feature of $D$. caninum (Soulsby, 1982). Dogs were administered with praziquantel @ 10 $\mathrm{mg} / \mathrm{kg}$ body weight orally. After six hours of praziquantel 
oral administration of syrup containing liquid paraffin and milk of magnesia was advised in all the dogs. Dogs recovered uneventfully and they were free from the parasitic ova after the ninth day of revisit.

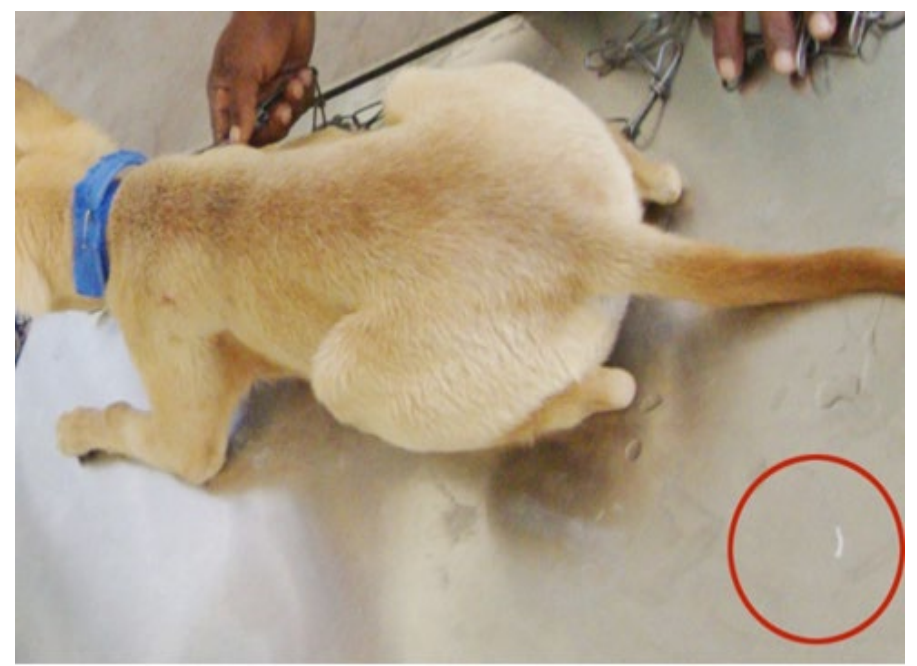

Figure 1: Gravid segments of the parasite

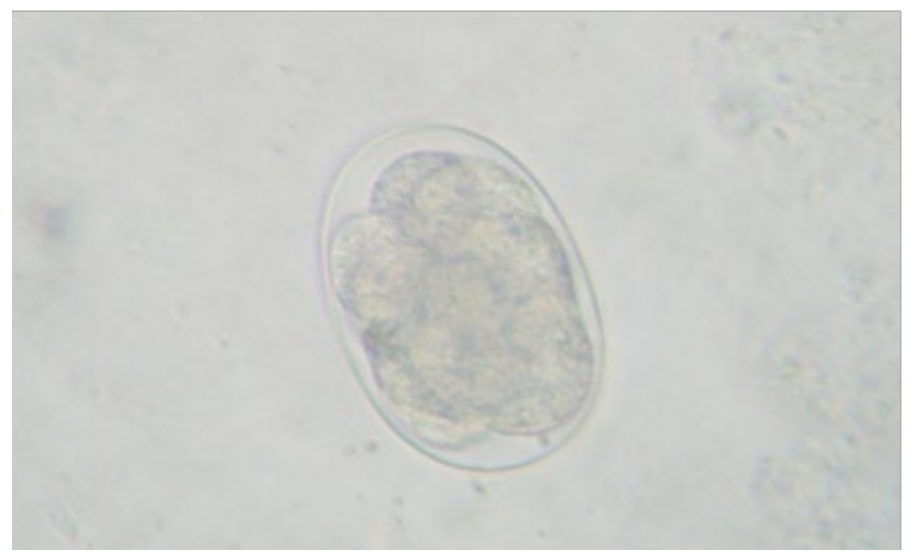

Figure 2: Dipylidium caninum single egg capsule (x400)

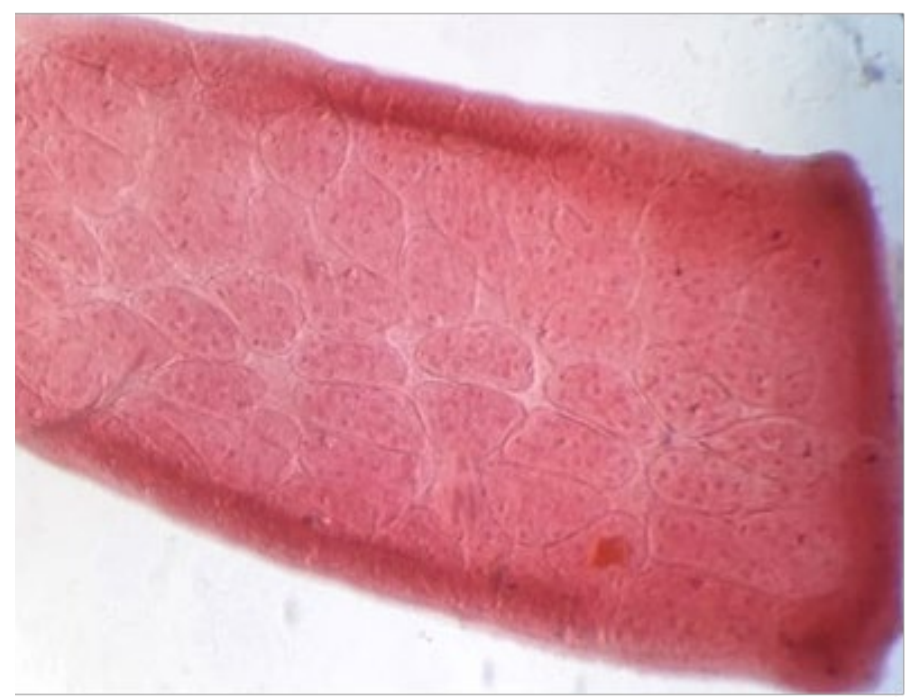

Figure 3: Microscopic view of Gravid segments (x40)

In the present study, the definite diagnosis was done by detection of eggs or egg packets in stool and it is due to rupture of proglottids in the intestine. Without eggs, it is difficult to go for a confirmative diagnosis of the condition. The egg packets are expelled through the bilateral genital pores or these egg packets are released after the proglottids dehydrate and rupture in the environment (Saini et al., 2016). The eggs might be ingested by the larvae of dog or cat fleas. The oncosphere hatches in the gut of the arthropod, burrows through the wall and develops into the infective cysticercoid in the hemocoel when the flea metamorphoses into the parasitic adult stage (Wani et al., 2015). Infected fleas are eaten by pet dogs, larval forms are stick to the teeth and saliva will be infected. The larval stage tapeworm is liberated in the intestines of dog and matures into an adult tapeworm. The mature proglottids of this parasite resembling cucumber seed shape and voided during the process of defecation. Pet owners and the kids may get the accidental contamination of the saliva and may accidentally ingest the infective larval forms and becomes as an adult tapeworms (Ramana et al., 2011). In the present study, dogs showed the specific signs including of watery diarrhoea, progressive emaciation and scooting behaviour. This is because adult tapeworm attaches to the intestine in dogs and cause haemorrhage which further causes enteritis and loss of body weight. Scooting behaviour is due to itching of the anus caused by the passing of gravid segments. Disease can be controlled by the control of fleas and lice by the advanced methods of parasitic control and by owner education about the zoonotic importance of parasites (Sivajothi and Reddy, 2018).

\section{SUMMARY}

In conclusion, regular screening for endoparasites and deworming schedule is recommended in adult dogs because repeated infection can occur throughout life.

\section{ACKNOWLEDGEMENTS}

The authors are thankful to the authorities of the Sri Venkateswara Veterinary University for the facilities provided during the study.

\section{CONFLICT OF INTEREST}

Both the authors have no conflict of interest regarding publication of the article.

\section{AUTHORS CONTRIBUTION}

Both the authors had equal role for the study. S.Sivajothi diagnosed the condition and prepared the manuscript for submission. B.Sudhakara Reddy had done the clinical recordings and edited the manuscript. 


\section{REFERENCES}

- Moudgil AD, Mittra S, Agnihotri RK, Sharma D, Sen D (2016) Prevalence of gastrointestinal parasites in dogs of Palampur, Himachal Pradesh. J. Parasit. Dis. 40(2): 227-229 https://doi.org/10.1007/s12639-014-0480-0.

- Narasimham MV, Panda P, Mohanty I, Sahu S, Padhi S, Dash M (2013). Dipylidium caninum infection in a child: a rare case report. Indian J. Med. Microbiol. 31(1):82-84. https:// doi.org/10.4103/0255-0857.108738

- Ramana KV, Rao SD, Rao R, Mohanty SK, Wilson CG (2011). Human dipylidiasis: a case report of Dipylidium caninum infection from Karimnagar. Online J. Hlth. Allied Sci. 10(2):28.

- Saini VK, Gupta S, Kasondra A, Rakesh RL, Latchumikanthan
A (2016) Diagnosis and therapeutic management of Dipylidium caninum in dogs: a case report. J. Parasit. Dis. 40 (4): 1426-1428. https://doi.org/10.1007/s12639-015-0706-

- Sivajothi S, Reddy BS (2018). A review on parasitic castration in veterinary Parasitology. J. Entomol. Zool. Studies. 6(1): 635-639.

- Soulsby EJL (1982). Helminths, Arthropods and Protozoa of domesticatedanimals. Bailliere Tindall, London. Pp 763766.

-Wani ZA, Allaie IM, Shah BM, Raies A, Athar H, Junaid S (2015). Dipylidium caninum infection in dogs infested with fleas. J. Parasit. Dis. 39(1):73-75. https://doi.org/10.1007/ s12639-013-0281-x 